\title{
Experimental Demonstration of 32 Gbaud 4-PAM for Data Center Interconnections of up to $320 \mathrm{~km}$
}

Madsen, Peter; Suhr, Lau Frejstrup; Clausen, Anders; Tafur Monroy, Idelfonso

Published in:

Proceedings of Asia Communications and Photonics Conference

Publication date:

2017

Document Version

Peer reviewed version

Link back to DTU Orbit

Citation (APA):

Madsen, P., Suhr, L. F., Clausen, A., \& Tafur Monroy, I. (2017). Experimental Demonstration of 32 Gbaud 4PAM for Data Center Interconnections of up to $320 \mathrm{~km}$. In Proceedings of Asia Communications and Photonics Conference

\section{General rights}

Copyright and moral rights for the publications made accessible in the public portal are retained by the authors and/or other copyright owners and it is a condition of accessing publications that users recognise and abide by the legal requirements associated with these rights.

- Users may download and print one copy of any publication from the public portal for the purpose of private study or research.

- You may not further distribute the material or use it for any profit-making activity or commercial gain

- You may freely distribute the URL identifying the publication in the public portal 


\title{
Experimental Demonstration of 32 Gbaud 4-PAM for Data Center Interconnections of up to $320 \mathrm{~km}$
}

\author{
Peter Madsen, Lau F. Suhr, Anders T. Clausen, Idelfonso Tafur Monroy \\ Technical University of Denmark, Ørsteds Plads, bygning 343, 2800 Kgs. Lyngby, Denmark \\ petma@fotonik.dtu.dk
}

\begin{abstract}
This paper presents experimental results demonstrating a 64 Gbps 4-PAM transmission over a $320 \mathrm{~km}$ SSMF span employing standard $80 \mathrm{~km}$ fiber spans for metro links. The receiver consists of a LPF and a DFE utilizing the DD-LMS algorithm.
\end{abstract}

OCIS codes: $060.2330,060.4080,060.4510$.

\section{Introduction}

Resulting from the need of constant connectivity of today's society, more and bigger data centers are sprouting up in cities around the world. New data centers are designed to handle the ever increasing data demands, while older data centers will experience a potential bottleneck effect especially in the connections between data centers sites [1]. In a scenario where two data centers are interconnected using a long distance, high bitrate link it is desirable to be able to generate a high-speed 4-PAM signal in a rack in data center A and transmit it through a long range, uninterrupted link to a rack in data center B. It is believed that in the near future this interconnection of data centers is being pushed towards $400 \mathrm{GbE}$ by the strong demand for data center switching fabrics beyond $10 \mathrm{GbE}, 40 \mathrm{GbE}$, and $100 \mathrm{GbE}$ connectivity. But when it comes to interconnects there is a gap between the capabilities of client-side and long-haul optics, caused by the scaling trends in the data center business [2]. Long-haul optics have both the capacity and reach needed for data center interconnects, but most long-haul technologies are considered to be too expensive and complex. Client-side optics is more affordable but do not offer the needed reach and capacity for data center interconnects [3]. In recent years 4-PAM has received a lot of attention in metro- and access networks as a low complexity solution that can carry the higher bitrates that makes simpler scheme like NRZ unsuitable because of the high baudrate needed. This coincides with the development of $200 \mathrm{GbE}$ and $400 \mathrm{GbE}$ standards such as IEEE P802.3bs [4] where 4-PAM is being considered as the used modulation format, as IM-DD keeps the complexity and cost of the system low compared to coherent techniques currently used in long-haul transmission. High baud rates using 4-PAM have been proven possible but at a short transmission distance $(10 \mathrm{~km})$ [5]. In cases where 4-PAM modulation have been used for longer transmission distances (100-400 km) the symbol rates have been lowered to 20 Gbaud [6] or a combination of lower symbol rates and special Vertical Cavity Surface Emitting Laser (VCSEL) arrays have been developed to transmit the 4-PAM on multiple wavelengths [7].

In this paper, we experimentally demonstrate transmission of 32 Gbaud 4-level Pulse Amplitude Modulation (4PAM) over $320 \mathrm{~km}$ Standard Single Mode Fiber (SSMF) using a simple Intensity Modulation and Direct Detection (IM-DD) modulation scheme. additionally, the transmitter is based on an Electro Absorption Modulator (EAM) which has a low cost and small footprint. We implement post-equalization and keep the conventional transmission link design unchanged to allow for easy upgrade of existing links.

\section{Setup}

This section presents the experimental setup that was used to demonstrate 32 Gbaud 4-PAM over $320 \mathrm{~km}$ SSMF. The experimental setup is depicted in Fig. 1. The 32 Gbaud 4-PAM was created, using a Pulse Pattern Generator (PPG) generating a PRBS with length $2^{15}$ (PRBS15) as a $32 \mathrm{Gbit} / \mathrm{s}$ Non Return to Zero (NRZ) on two uncorrelated channels. The two NRZ signals was multiplexed into a 32 Gbaud 4-PAM signal using a 32 Gbaud Digital-to-Analog Converter (DAC). A delay line was inserted between the clock and the DAC in order to adjust the sampling time. The 4-PAM signal was amplified to a peak to peak power of $2 \mathrm{~V}$ after the $6 \mathrm{~dB}$ attenuator, and applied to an EAM with a bandwidth of $40 \mathrm{GHz}$. The $6 \mathrm{~dB}$ attenuator (Att.) before the EAM, minimized the electrical reflections and ensured optimum Radio Frequency (RF) input. The EAM was packaged with a Continuous Wave(CW) laser source. The CW laser source was temperature controlled to emit at $1553.0 \mathrm{~nm}$ and the emitted optical output power of the modulated 


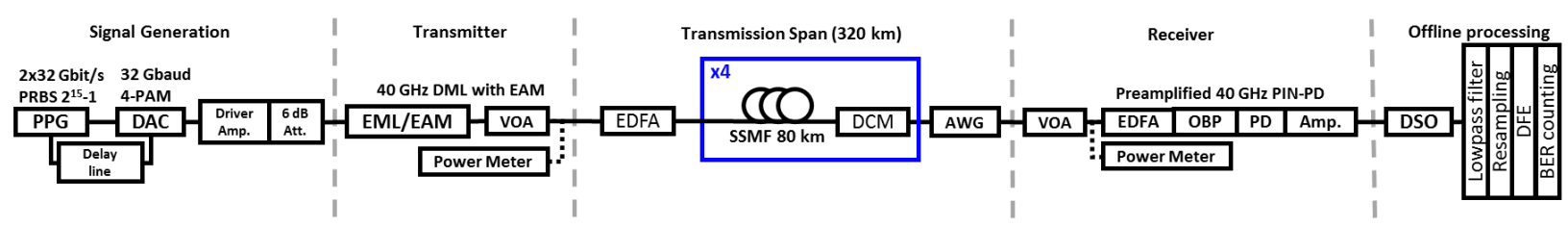

Fig. 1. Experimental setup for 32 Gbaud 4-PAM transmission over $320 \mathrm{~km}$ SSMF for inter-data center connectivity. The DCM module also contains an EDFA to amplify the signal power.

signal was $3.75 \mathrm{dBm}$. At the output of the optical transmitter a Variable Optical Attenuator (VOA) was placed, in order to control transmission power and limit non-linearities in the transmission span.

The transmission span consisted of $80 \mathrm{~km}$ SSMF followed by a Dispersion Compensating Module (DCM) which included an Erbium Doped Fiber Amplifier (EDFA) with $20 \mathrm{dBm}$ output power and $6 \mathrm{~dB}$ noise figure. The DCM compensated for $\sim 100 \%$ dispersion and fiber losses of the $80 \mathrm{~km}$ SSMF. The $80 \mathrm{~km}$ SSMF and DCM span could be concatenated up to 4 times to reach a maximum transmission distance of $320 \mathrm{~km}$. As the transmission span was originally designed for transmission of 32 Wavelength Division Multiplexing (WDM) channels, an Arrayed Waveguide Grating (AWG) was used to extract the transmitted wavelength. The AWG had a $100 \mathrm{GHz}$ channel grid, with a resulting $\sim 50 \mathrm{GHz} 3 \mathrm{~dB}$ bandwidth, with a total of 32 channels.

After the transmission span a VOA was used to enable Bit Error Rate (BER) measurements. The optical-electrical conversion was done by a preamplified $40 \mathrm{GHz}$ PIN Photo Diode (PIN-PD). The preamplifier step consisted of an EDFA with constant pump power and an Optical Band-Pass (OBP) filter with a $0.9 \mathrm{~nm}$ bandwidth in order to filter out the Amplified Spontaneous Emission (ASE). After the PD the electrical signal was amplified $26 \mathrm{~dB}$ before being sampled at $80 \mathrm{GSa} / \mathrm{s}$ by the Digital Storage Oscilloscope (DSO). The DSO was used to store traces for offline processing and for each attenuation step 1 million bits was demodulated. The Digital Signal Processing (DSP) consisted of lowpass filtering and resampling of the signal. Furthermore, a Decision-Feedback Equalizer (DFE) with 41 forward and 21 feedback taps, spaced at half the symbol rate, was used to equalize the signal. The DFE was controlled by a Decision-Directed Least-Mean-Square (DD-LMS) algorithm. After the equalization the BER was calculated by bit-by-bit counting.

\section{Results}

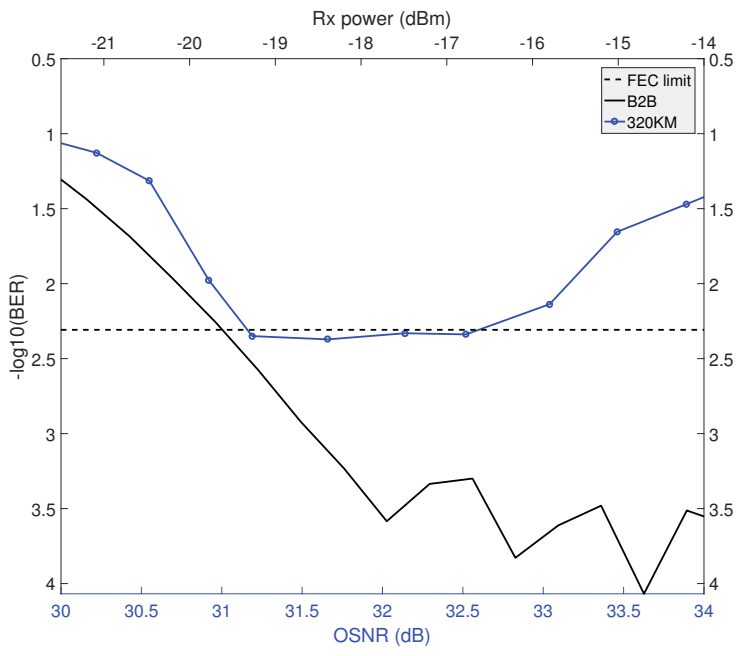

Fig. 2. The BER curves for the back-to-back case and the $320 \mathrm{~km}$ span transmission. The blue and dotted curve shows the BER against OSNR for the $320 \mathrm{~km}$ transmission while the black curve shows the back-to-back transmission BER for different receiver powers. 


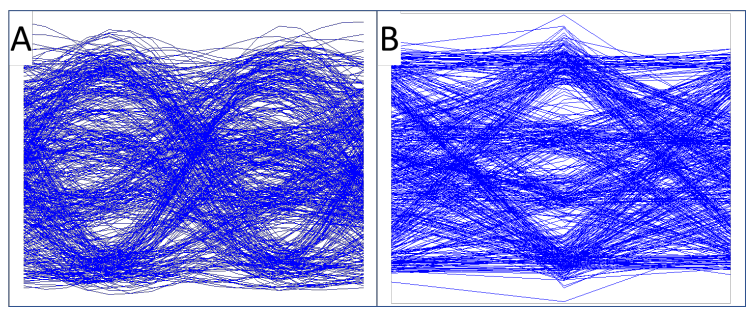

Fig. 3. The eye-diagrams for the best BER corresponding to an OSNR of $31.66 \mathrm{~dB}$. A: The eyediagram after low-pass filtering and resampling. B: The eye-diagram after the DFE.

The results of the transmission over the span is shown in Fig. 2. In the Figure the black curve shows the BER from the back-to-back measurements while the blue dotted curve shows the BER after the span transmission. As the back-to-back case employs two EDFAs there is an error floor at $\sim 3.5$ on the -log scale. After transmission ic can be observed that below the $11 \%$ OH FEC [8] level transmission, at $\sim 2.3$ on the -log scale, can be achieved for an OSNR of between $\sim 31.2-\sim 32.5 \mathrm{~dB}$. The relatively small difference between the error floor of the span transmission and the back-to-back case is attributed to the fact that the AWG employed in the span was not used for the back-to-back case. As the AWG had a grid of $100 \mathrm{GHz}$ its 3 -dB cutoff was $\sim 50 \mathrm{GHz}$ which is lower than the cutoff of the OBP filter used in the receiver. Therefore less noise was removed by the receiver filter than the AWG leading to the smaller difference between the two measuring scenarios. Fig. 3 shows the eye-diagrams for the best BER scenario at an OSNR of 31.66 $\mathrm{dB}$ after DSP filtering and after the DFE. As can be seen the DFE gives a significant improvement to the middle and upper eye opening while also aligning the eye openings vertically.

\section{Conclusion}

An experimental validation of 32-Gbaud 4-PAM over a $320 \mathrm{~km} \mathrm{SSMF} \mathrm{link} \mathrm{was} \mathrm{achieved} \mathrm{through} \mathrm{the} \mathrm{use} \mathrm{of} \mathrm{a} \mathrm{simple}$ IM-DD scheme. The transmitter used a EAM with a CW light source in a single simple package while the receiver side DSP consisted of a low-pass filter along with a DFE equalizer after a direct detection PD. The transmission span employed 5 EDFAs and 4 DCMs to compensate power loss and dispersion from the SSMF. After DFE equalizer error free transmission is possible by implementing an $11 \%$ OH FEC.

\section{Acknowledgements}

This research has been supported by the Villums Fonden through the SEES project.

\section{References}

\section{References}

1. Y. Takita et al. "Towards Seamless Service Migration in Network Re-Optimization for Optically Interconnected data centers," Optical Switching and Networking, No. 22, 2016, p. 9-17.

2. J. Theodoras, "Terabit for Data Centers," ADVA Optical Networking, Lightwave (Online), 2017, http:// www.lightwaveonline.com/articles/2017/01/terabit-for-data-centers.html

3. A. Larsson et al. "VCSEL design and integration for high-capacity optical interconnects," Proc. SPIE, Optical Interconnects XVII, Vol. 101090, 2017.

4. The homepage of IEEE P802.3bs $400 \mathrm{~Gb} / \mathrm{s}$ Ethernet Task Force, http: / / http: //www. ieee802. org/ $3 / \mathrm{bs} /$

5. S. Kanazawa et al., "Transmission of 214-Gbit/s 4-PAM signal using an ultra-broadband lumped-electrode EADFB laser module," Optical Fiber Communication Conference Postdeadline Papers, OSA Technical Digest (online), Optical Society of America, 2016, paper Th5B.3.

6. J. L. Wei et al., "Demonstration of the First Real-Time End-to-End 40-Gb/s PAM-4 for Next-Generation Access Applications using 10-Gb/s Transmitter," Journal of Lightwave Technology, Vol. 34, No. 7, 2016, p. 1628-1635.

7. C. Xie et al., "400-Gb/s PDM-4PAM WDM System Using a Monolithic 2x4 VCSEL Array and Coherent Detection," in Journal of Lightwave Technology, vol. 33, no. 3, 2015, p. 670-677.

8. ITU-T Forward error correction for high bit-rate DWDM submarine systems, G.975.1,02/2004 